\title{
Oncostatin M activates STAT3 to promote endometrial cancer invasion and angiogenesis
}

\author{
MINJIAO ZHU ${ }^{1}$, QI CHE $^{1}$, YUN LIAO $^{2}$, HUIHUI WANG $^{1}$, JINGYUN WANG $^{2}$, \\ ZHENG CHEN $^{1}$, FANGYUAN WANG ${ }^{1}$, CHENJUN DAI $^{1}$ and XIAOPING WAN ${ }^{2}$ \\ ${ }^{1}$ Department of Obstetrics and Gynecology, Shanghai First People's Hospital Affiliated to \\ Shanghai Jiao Tong University, Shanghai; ${ }^{2}$ Department of Obstetrics and Gynecology, \\ Shanghai First Maternity and Infant Hospital Affiliated to Tong Ji University, Shanghai, P.R. China
}

Received January 11, 2015; Accepted April 3, 2015

DOI: 10.3892/or.2015.3951

\begin{abstract}
Oncostatin M (OSM), a pleiotropic cytokine, can either promote or inhibit the growth of tumors derived from specific tissues. However, little is known about the activity and expression pattern of OSM in endometrial cancers (ECs). Herein we show that expression of OSM in human ECs was significantly higher than that in hyperplastic or normal tissues. In EC tissues, high OSM levels were positively correlated with tumor stage, histological grade, myometrial invasion, and lymph node metastasis. Additionally, we demonstrated that recombinant human OSM (rhOSM) promoted tumor angiogenesis in EC cell lines by activating STAT3 (signal transducer and activator of transcription 3) and enhanced both cell migration and cell invasion. rhOSM did not, however, influence the proliferation of EC cells in vitro. In contrast, in our in vivo xenograft model, overexpression of rhOSM promoted cell proliferation, tumor growth, and angiogenesis in nude mice. Collectively, these experiments suggest that OSM may be a tumor promoter that encourages EC progression. OSM may thus serve as a potential target of antiangiogenic therapy for endometrial cancer.
\end{abstract}

\section{Introduction}

Endometrial cancer (EC) is one of the most common gynecologic malignancies, with an estimated 49,500 new cases and 8200 deaths in 2013 in the United States (1). ECs are classified into two groups: those that are estrogen related (type I, endometrioid) and those that are not estrogen related (type II, non-endometrioid). Type I ECs are usually linked to obesity, hormone-receptor positivity, and a favorable outcome. In

Correspondence to: Dr Xiaoping Wan, Department of Obstetrics and Gynecology, Shanghai First Maternity and Infant Hospital Affiliated to Tong Ji University, No. 536, Chang Le Road, Jing'an District, Shanghai 200040, P.R. China

E-mail:wanxp@sjtu.edu.cn

Key words: Oncostatin M, endometrial cancer, STAT3, angiogenesis contrast, type II ECs are more common in older, non-obese women and have a worse prognosis (2). Current treatment, including hysterectomy, hormonal therapy, and chemotherapy, are only effective for early-stage ECs. Effective target therapies are not available for patients with high-grade diagnoses, especially for individuals with undifferentiated tumors with deep muscle infiltration (3). Despite the prevalence of this cancer, molecular mechanisms accounting for the development and metastasis of EC remain unclear. To allow for the possibility of targeted therapies for later-stage EC, further exploration into the molecular mechanisms underlying EC progression would be beneficial.

Oncostatin M (OSM) is a member of the IL-6 family of cytokines produced by macrophages, monocytes, $\mathrm{T}$ cells, neutrophils, and several other cell types $(4,5)$. OSM inhibits the growth of cells from several types of solid tumor, including breast tumor, melanoma, and osteosarcoma (6-8). In contrast, OSM promotes the proliferation of cells from other tumor types, including those derived from prostate, cervical, and ovarian cells (9-11). These results suggest that OSM may have different roles depending on the tumor cell type. The role that OSM plays in EC has not been clearly defined.

OSM signals through a heterodimeric receptor composed of gp130 and either OSM receptor-b (OSMR) or the leukemia inhibitory factor receptor (LIFR). These signal via Janus kinases (JAKs) to activate the STAT3 (signal transducer and activator of transcription 3), PI3K (phosphatidylinositol3-kinase), and MAPK (mitogen-activated protein kinase) cascades (12-14). Increased STAT3 activity in tumor cells upregulates VEGF expression and enhances angiogenesis (15), which has a major role in tumor growth, progression, and metastasis $(16,17)$. However, it remains unclear whether OSM contributes to the development and progression of EC and, if it does, what the mechanism of its action is, especially with respect to angiogenesis, which involves the STAT3/VEGF pathway.

In this study, we sought to explore the functional, mechanistic roles of OSM in EC. We analyzed OSM expression in paraffin-embedded tissue sections and function in multiple cellular contexts and assayed its effects in tumor-bearing nude mice. We showed that OSM promoted EC progression. In particular, OSM promoted angiogenesis in a STAT3-dependent 
manner and, therefore, may serve as a potential marker for antiangiogenic therapy selection.

\section{Materials and methods}

Acquisition of tissue specimens. Paraffin-embedded tissue samples were obtained from patients who were treated at the Shanghai First People's Hospital Affiliated to Shanghai Jiao Tong University, Shanghai, China. The project was approved by the Human Investigation Ethics Committee of the Shanghai First People's Hospital, and informed consent were obtained from all patients prior to the onset of the study. We obtained 73 EC tissue specimens from patients who underwent initial hysterectomy, 26 normal endometrial samples from patients who underwent hysterectomy to treat other diseases such as myoma or adenomyosis, and 20 atypical hyperplastic tissue specimens from patients who underwent hysteroscopic examination due to irregular bleeding. The stages (I-IV) and histological grades (G1-G3) of these tumors were established according to the criteria of the International Federation of Gynecology and Obstetrics (FIGO) surgical staging system (18). None of the patients had undergone hormone therapy, radiotherapy, or chemotherapy before surgery. The clinicopathological characteristics of the EC patients participating in our study are presented in Table I.

Immunohistochemistry analysis. All samples were prepared and analyzed with the Histostain-Plus kit (rabbit) (MRBiotech, Emeryville, CA, USA) according to the manufacturer's protocol. Staining was performed on paraffin-embedded specimens using primary antibodies as follows: anti-OSM (1:100; Boster, Wuhan, China). After $16 \mathrm{~h}$ of incubation, the sections were incubated with a biotinylated secondary antibody (MRBiotech). We then added a horseradish peroxidase-conjugated avidinbiotin complex to the sections. OSM expression was detected by diaminobenzidine as per the manufacturer's instructions. The staining percentage was scored in the following manner: $0,0-5 \% ; 1,5-25 \% ; 2,25-50 \% ; 3,50-75 \%$; and $4,75-100 \%$. The staining intensity was scored as follows: 0 , negative; 1 , weak; 2 , moderate; 3 , strong. Then, immunoreactivity scores for each case were obtained by multiplying the values of the two parameters described above. As a negative control, phosphatebuffered saline (PBS) was used to replace the primary antibody.

Microvessel density (MVD) was assessed by immunostaining for CD34 (Abcam, Cambridge, UK), which highlights the tumor/tissue vascularity. The microvessels were counted in three fields per section. The positive-stained blood vessels in the selected areas were analyzed at x400 magnification.

Cell culture. The human EC cell lines Ishikawa and HEC-1B were used (American Type Culture Collection, Manassas, VA, USA). The human umbilical vascular endothelial cells (HUVECs) that we used were obtained from Key-Gen Biotech (Nanjing, China). Ishikawa and HEC-1B cells were maintained according to the supplier's instructions in DMEM/F12 (Gibco, Auckland, New Zealand) supplemented with $10 \%$ fetal bovine serum (FBS) (HyClone, Logan, UT, USA). HUVECs were grown in RPMI-1640 (Gibco) supplemented with 10\% FBS. Cells were cultured in a humidified atmosphere with $95 \%$ air $/ 5 \% \mathrm{CO}_{2}$ at $37^{\circ} \mathrm{C}$.
$R N A$ extraction and quantitative real-time PCR. Total RNA was prepared from the EC cell lines using TRIzol RNA isolation reagents (Invitrogen, Carlsbad, CA, USA), and cDNA was then generated with the Prime Script RT reagent kit (Takara Inc., Otsu, Japan), using the manufacturer's instructions. A $10-\mu 1$ PCR reaction with single-stranded cDNA as the template was carried out with 40 cycles of denaturation $\left(95^{\circ} \mathrm{C}\right)$ for $5 \mathrm{sec}$, annealing $\left(60^{\circ} \mathrm{C}\right)$ for $34 \mathrm{sec}$, and elongation $\left(60^{\circ} \mathrm{C}\right)$ for $30 \mathrm{sec}$ using SYBR Premix Ex Taq (Takara Inc.). The primer sequences are listed in Table II. For all qPCR experiments, values on the y axis represent $2^{(-\Delta \mathrm{Ct})}$, where $\Delta \mathrm{Ct}$ is the difference between the $\mathrm{Ct}$ for the gene of interest and the $\mathrm{Ct}$ for the gene used for normalization. All data were obtained in triplicate from three independent experiments.

Enzyme-linked immunosorbent assay (ELISA). VEGF and OSM protein levels were detected in the culture medium using solid-phase sandwich ELISA assays as per the manufacturer's instructions (DVE00, R\&D Systems, Minneapolis, MN, USA and EK0478, Boster). According to the manufacturer, the VEGF assay sensitivity was $0.7 \mathrm{pg} / \mathrm{ml}$, and the assay range was $15.6-1000 \mathrm{pg} / \mathrm{ml}$. The OSM assay sensitivity was $0.7 \mathrm{pg} / \mathrm{ml}$, and the assay range was $15.6-1000 \mathrm{pg} / \mathrm{ml}$. Culture medium was collected three times independently for statistical analysis.

Western blot analysis. Total protein was extracted using a RIPA kit (Beyotime, Shanghai, China) containing a $1 \%$ dilution of the protease inhibitor phenylmethylsulfonyl fluoride (Beyotime) as per the manufacturer's instructions. Total protein concentration was estimated using the BCA method (Pierce, Rockford, IL, USA) as per the manufacturer's instructions. Similar amounts of protein were analyzed in each lane of a $10 \%$ SDS-polyacrylamide gel. Proteins were then transferred onto nitrocellulose membranes. After transfer, membranes were blocked with $5 \%$ bovine serum albumin (BSA)/ phosphate-buffered saline (PBS) for $2 \mathrm{~h}$. The membranes were incubated with primary antibodies at $4{ }^{\circ} \mathrm{C}$ overnight. The membranes were then incubated with peroxidase-linked secondary antibody (1:10,000; Epitomics, Burlingame, CA, USA) for $2 \mathrm{~h}$ at room temperature. Proteins were then detected by enhanced chemiluminescent reagents. GAPDH was used as an internal control.

Primary antibodies included: rabbit anti-STAT3 (1:1000; Cell Signaling Technology, Beverly, MA, USA), rabbit antipSTAT3(1:1000; Cell Signaling Technology) and rabbit anti-GAPDH (1:2000; Epitomics).

Stable transfection of HEC-1B cells. To stably express OSM, HEC-1B cells were washed with PBS and switched to antibiotic-free growth medium for $24 \mathrm{~h}$ before transfection. All transfections used Lipofectamine 2000 reagent (Invitrogen) as per the manufacturer's instructions. The plasmid that overexpressed OSM and the negative control (NC) plasmid were generated by GeneChem (Shanghai, China), the transfection reagent was obtained from Qiagen (Shanghai, China). The plasmid was transfected into HEC-1B cells $(1.6 \mu \mathrm{g} / \mathrm{ml})$, and then the cells were selected with G418 (1 mg/ml; Gibco, Carlsbad, CA, USA) in the growth medium and resistant clones were chosen. 

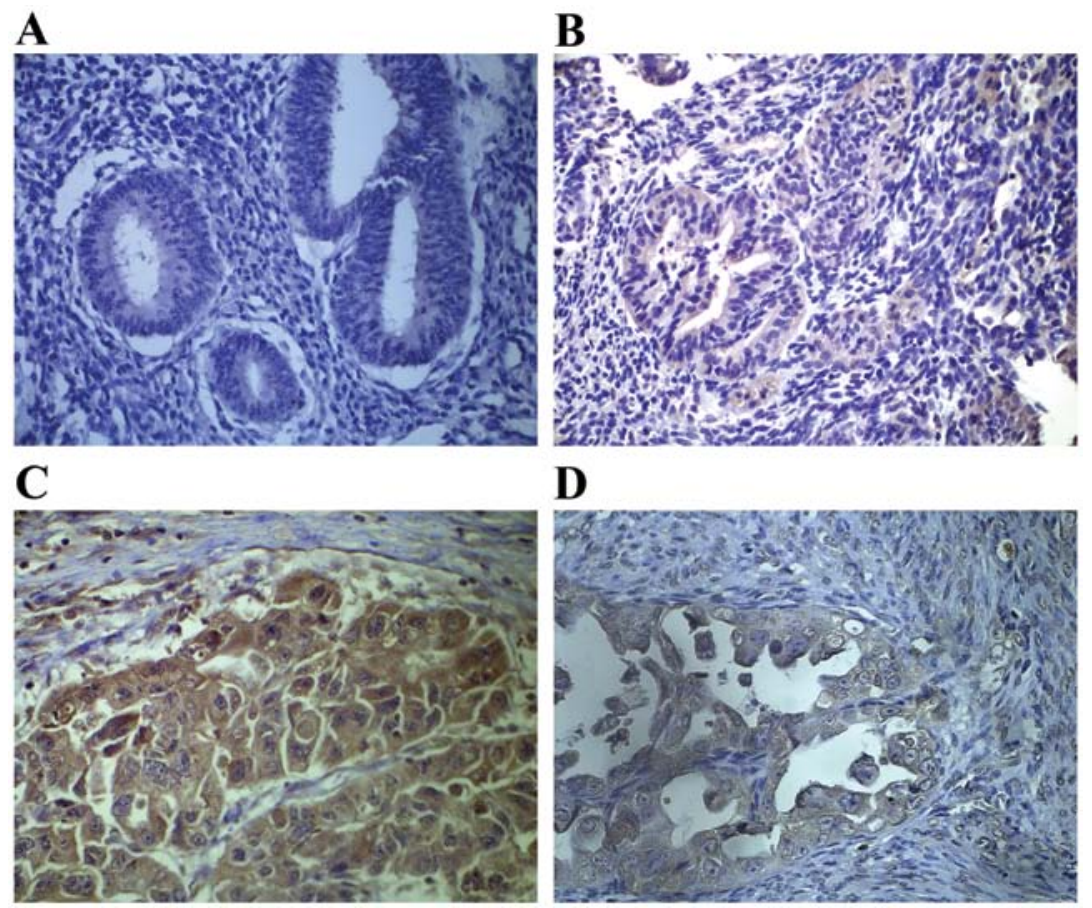

D

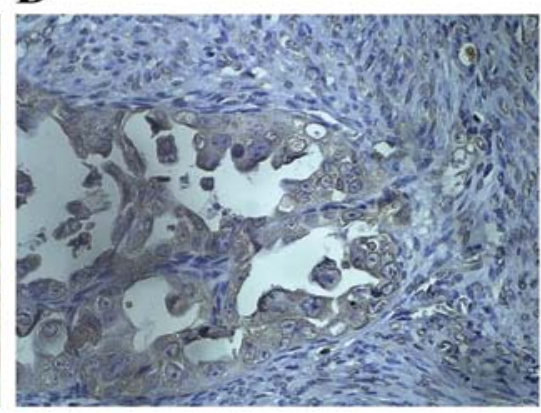

Figure 1. Oncostatin M (OSM) expression in human endometrial tissue specimens. Representative micrographs of OSM staining in endometrial tissues (magnification, $\mathrm{x} 400$ ). Immunohistochemical staining for OSM in normal endometrium (A), atypical hyperplastic endometrium (B), endometrioid endometrial cancer (EEC) (C), and papillary serous endometrial cancer (EC) (D).

Cell migration and invasion assays. After being trypsinized, centrifuged, and resuspended, cells were seeded in serum-free medium in the upper compartment of individual transwell chambers $(8-\mu \mathrm{m}$ pore size; BD Biosciences, San Jose, CA, USA) with or without Matrigel coating (BD Biosciences) at a density of $1 \times 10^{5}$ cells/well (for the migration assay) or $2 \times 10^{5}$ cells/well (for the invasion assay). The lower chamber was filled with $600 \mu 1$ of culture medium containing 5\% FBS (C5), C5 with $40 \mathrm{ng} / \mathrm{ml} \mathrm{rhOSM}$ (C5/rhOSM), or C5 with $40 \mathrm{ng} / \mathrm{ml} \mathrm{rhOSM}$ and $1 \mu \mathrm{M}$ WP1066, a STAT3 inhibitor (C5/rhOSM/WP1066). After $24 \mathrm{~h}$ of incubation, cells that had failed to invade were removed from the upper chamber. Those that were attached to the outside of the membrane were fixed and stained with $5 \%$ crystal violet and counted at x200 magnification. Six random fields were selected for each membrane, and results are expressed in terms of the number of cells per field. The migration and invasion assays were repeated at least three times.

Evaluation of cell proliferation. Cell proliferation was evaluated with a CCK8 (Obio Technology, Shanghai, China) assay as per the manufacturer's instructions. Cells $\left(2 \times 10^{3}\right.$ cells/well $)$ were plated in 96-well plates and were then cultured for 24 , 48 , or $72 \mathrm{~h}$. At each time point, $10 \mu \mathrm{l}$ of CCK8 stock solution was added to each well, and the plates were further incubated for $2 \mathrm{~h}$ at $37^{\circ} \mathrm{C}$. The absorbance was detected at $450 \mathrm{~nm}$ in a microplate reader.

Tumorigenicity assays in nude mice. Female 4-week-old athymic nude BALB/c mice were obtained from Shanghai First People's Hospital Affiliated to Shanghai Jiao Tong University, Shanghai, China. HEC-1B cells stably transfected with the OSM expression plasmid or the NC plasmid were suspended in
PBS ( $1 \times 10^{7}$ cells in $200 \mu 1$ PBS) and injected into the subcutaneous tissue of the mice. Tumor size was measured weekly for a 5-week period. At 35 days post-injection, mice were euthanized, and their weights and tumor volumes were measured prior to further histological evaluation. The tumor volumes were calculated by using the following standard formula: tumor volume $\left(\mathrm{cm}^{3}\right)=$ (the longest diameter) $\mathrm{x}$ (the shortest diameter $)^{2} \times 0.5$. All experimental protocols were approved by the Ethics Committee for Animal Experimentation of Shanghai Jiao Tong University.

HEC-1B conditioned medium (CM) and mouse Matrigel plug assays. HEC-1B cells were grown in C10. After 24 h, C10 was removed and replaced with culture medium without FBS $(\mathrm{C} 0)$, $\mathrm{C} 0$ with $40 \mathrm{ng} / \mathrm{ml} \mathrm{rhOSM}$ (C0/rhOSM), or C0 with $40 \mathrm{ng} / \mathrm{ml}$ rhOSM and $1 \mu \mathrm{M}$ WP1066 (C0/rhOSM/WP1066). Samples of conditioned medium (CM) were obtained from each culture after an additional incubation of $24 \mathrm{~h}$.

For the plug assay, nine athymic nude BALB/c mice were randomly divided into three groups. Growth factor-reduced Matrigel (300 $\mu \mathrm{l}$; BD Biosciences) was mixed with CM (100 $\mu \mathrm{l})$ and injected subcutaneously into the flank of a mouse. Mice were euthanized 18 days after inoculation, and plugs were removed and photographed. Matrigel plugs were stained with hematoxylin and eosin (H\&E) for histological examination and were analyzed by immunohistochemistry as described above using antibodies against mouse CD34 (1:100, Abcam).

Tube formation assay. We coated a 96-well plate with $100 \mu \mathrm{l}$ Matrigel per well and incubated the plate at $37^{\circ} \mathrm{C}$ for $2 \mathrm{~h}$. Then, $2 \times 10^{4}$ HUVECs were suspended in $1 \mathrm{ml}$ diluted HEC-1B CM (dilution in 1:10) and applied to the pre-coated 96-well plate at a density of 2000 cells/well (19). After incubation at $37^{\circ} \mathrm{C}$ 

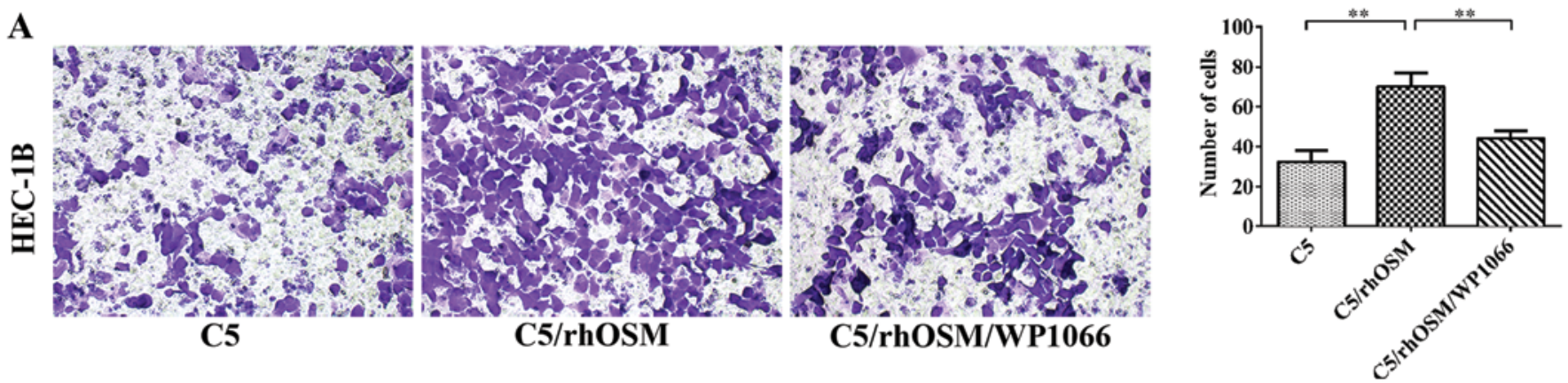

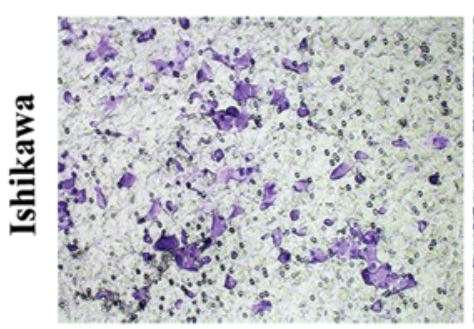

C5

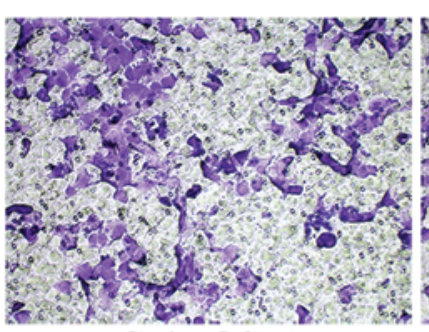

C5/rhOSM

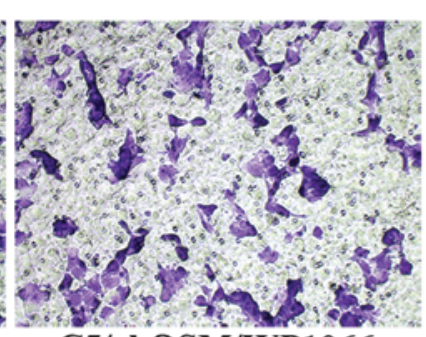

C5/rhOSM/WP1066

B

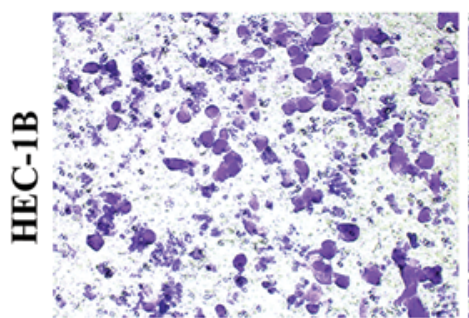

C5

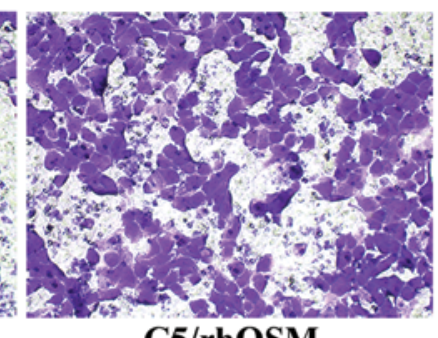

C5/rhOSM

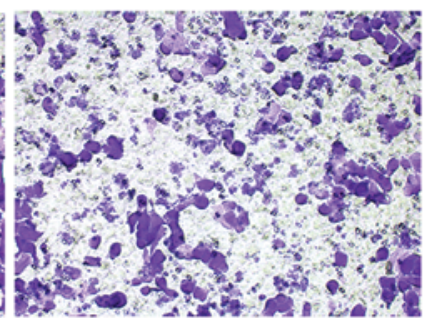

C5/rhOSM/WP1066

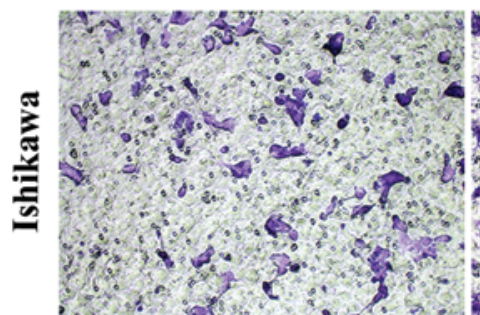

C5

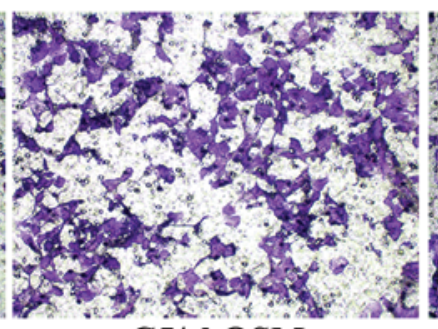

C5/rhOSM

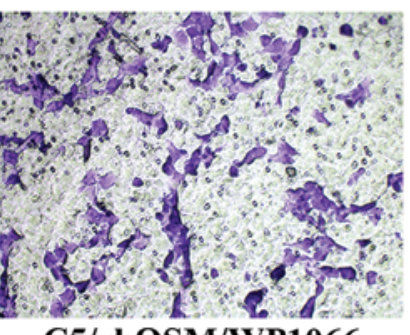

C5/rhOSM/WP1066
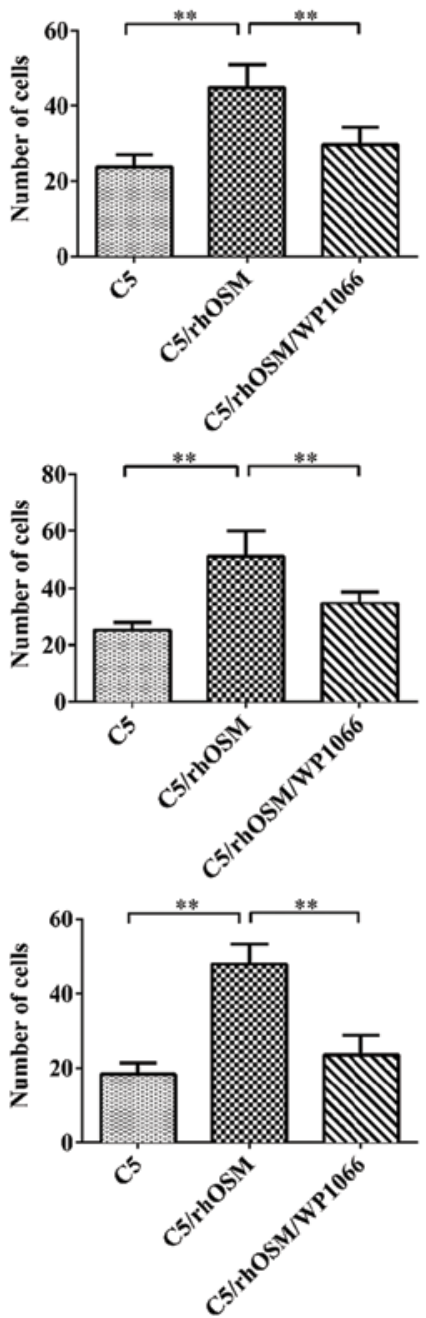

Figure 2. Effect of rhOSM on EC cell migration and invasion. In vitro migration (A) and invasion (B) assays using Transwell membranes with or without Matrigel coating. (A) Transwell migration assays of HEC-1B and Ishikawa cells in the absence and presence of rhOSM and with the addition of WP1066. Left, representative micrographs were taken at x200 magnification. Right, the number of migrating cells averaged from six random images from each treatment group at x200 magnification. (B) Transwell invasion assays of HEC-1B and Ishikawa cells with the same media as in (A). For both panels, left, representative micrographs were taken at x200 magnification, and, right, the number of invading cells were averaged across six random images from each treatment group at $\times 200$ magnification. The number of migrating or invading cells from three independent experiments is shown as the mean \pm SD in the right panel $\left({ }^{*} \mathrm{p}<0.05,{ }^{* *} \mathrm{p}<0.01\right)$.

for $16 \mathrm{~h}$, morphologic changes were observed under a microscope, and cells were photographed at x100 magnification. The total length of the capillary-like tubes that had formed was determined and averaged across three randomly selected microscope fields for each well.

HUVEC migration assays. To assess HUVEC migration ability, $5 \times 10^{4}$ cells suspended in $200 \mu 1$ of RPMI-1640 were seeded in the upper chamber of a Transwell. The lower chamber was filled with HEC-1B CM from different sources as described in the plug assay. After $24 \mathrm{~h}$ of incubation, cells were analyzed as described above for the cell migration and invasion assays.

Statistical analyses. All tests were carried out with SPSS 17.0 (Microsoft, Redmond, WA, USA) or Prism (GraphPad, San 
Table I. Correlation of OSM expression with clinicopathological parameters in endometrial carcinomas.

\begin{tabular}{|c|c|c|c|}
\hline \multirow[b]{2}{*}{ Characteristic } & \multirow[b]{2}{*}{ Case (n) } & \multicolumn{2}{|c|}{ OSM histoscore } \\
\hline & & Mean \pm SD & P-value \\
\hline Diagnostic categories & & & $0.002^{\mathrm{a}}$ \\
\hline Normal & 26 & $2.58 \pm 2.59$ & \\
\hline Hyperplasia & 20 & $4.45 \pm 2.27$ & \\
\hline Carcinoma & 73 & $6.52 \pm 4.30$ & \\
\hline Age & & & $0.480^{\mathrm{b}}$ \\
\hline$<60$ & 43 & $6.16 \pm 3.91$ & \\
\hline$\geq 60$ & 30 & $7.03 \pm 4.82$ & \\
\hline Histology & & & $0.255^{\mathrm{b}}$ \\
\hline Endometrioid & 58 & $6.79 \pm 4.15$ & \\
\hline $\begin{array}{l}\text { Non-endometrioid } \\
\text { (serous/clear) }\end{array}$ & 15 & $5.47 \pm 4.82$ & \\
\hline FIGO stage & & & $0.039^{b}$ \\
\hline Early (I or II) & 55 & $5.93 \pm 4.09$ & \\
\hline Late (III or IV) & 18 & $8.33 \pm 4.52$ & \\
\hline Histological grade & & & $\mathbf{0 . 0 3 8}^{\mathrm{b}}$ \\
\hline Low (1 or 2$)$ & 43 & $6.12 \pm 3.91$ & \\
\hline High (3) & 15 & $8.73 \pm 4.33$ & \\
\hline Myometrial invasion & & & $0.014^{b}$ \\
\hline$\leq 1 / 2$ & 53 & $5.77 \pm 4.36$ & \\
\hline$>1 / 2$ & 20 & $8.50 \pm 3.49$ & \\
\hline Lymph node metastasis & & & $0.042^{b}$ \\
\hline Positive & 22 & $8.05 \pm 3.48$ & \\
\hline Negative & 51 & $5.86 \pm 4.47$ & \\
\hline
\end{tabular}

The significance of differences (P-value) between categories was analyzed by ${ }^{a}$ Kruskal-Wallis rank test and ${ }^{b}$ Mann-Whitney $U$ test. Those with significant $\mathrm{P}$-values are in bold.

Diego, CA, USA). Each experiment was performed at least three times. Where applicable, data are shown as the mean \pm SD. Data were analyzed by unpaired Student's t-test or by one-way analysis of variance (ANOVA) for multiple comparisons. The Kruskal-Wallis rank test or Mann-Whitney $U$ test were used for comparisons of the categorical data. A P-value of $<0.05$ was considered statistically significant.

\section{Results}

Expression of OSM in tissues and its association with clinicopathological parameters. We assessed whether OSM is commonly upregulated in clinical EC samples. We chose 26 samples of normal endometrium tissue, 20 samples of atypical hyperplastic endometrium tissues, 57 cases of endometrioid endometrial cancer (EEC) tissue, and 16 cases of papillary serous EC or clear cell EC tissue. Immunohistochemistry showed that OSM expression was higher in atypical hyperplasias and even higher in ECs when compared with normal endometrial tissues (Fig. 1). We calculated a composite
Table II. Primer sequences for real-time PCR analysis

\begin{tabular}{ll}
\hline mRNA & \multicolumn{1}{c}{ Primer sequence } \\
\hline OSM & $\begin{array}{l}\text { Forward 5'-CGGACAGACAGACAGACACC-3' } \\
\text { Reverse 5'-GAGAACAGCCCAGAAGTTGG-3' }\end{array}$ \\
VEGFA & $\begin{array}{l}\text { Forward 5'-CCTTGCCTTGCTGCTCTACCTC-3' } \\
\text { Reverse 5'-TTCTGCCCTCCTCCTTCTGC-3' }\end{array}$ \\
\multirow{3}{*}{-actin } & $\begin{array}{l}\text { Forward 5'-CTGGGACGACATGGAGAAAA-3' } \\
\text { Reverse 5'-AAGGAAGGCTGGAAGAGTGC-3' }\end{array}$
\end{tabular}

histoscore to account for both stain intensity and uniformity to investigate whether the change in OSM expression in ECs was associated with specific clinical characteristics. We compared the association of OSM expression with the clinicopathological parameters of the EC cases (Table I). Our analyses indicated a significant association between increased OSM expression and the depth of myometrial invasion, lymph node metastasis, advanced disease stage (stages III or IV), and poor histological differentiation (grade 3) (all measurements resulted in $\mathrm{P}<0.05$; Table I). However, there was no significant difference in OSM expression when comparing endometrioid and non-endometrioid (i.e., serous and clear cell histological subtypes) ECs ( $\mathrm{P}=0.255$; Table I). These results suggested that OSM expression is related to the development of EC and to the risk-associated clinical features of the disease.

STAT3 is required for OSM-enhanced migration and invasion of EC cells. We next examined the effect of rhOSM on EC cell migration and invasion in vitro. Transwell migration and invasion assays were performed to study the migratory and invasive ability of EC cells (Fig. 2). rhOSM promoted cell migration and invasion in Ishikawa and HEC-1B cells $(\mathrm{P}<0.01)$. However, when the STAT3 inhibitor WP1066 was added, the effect was reversed. These results suggested that the effects of rhOSM in mediating EC cell migration and invasion are mediated by STAT3.

rhOSM does not directly promote cell viability in vitro. To investigate the potential role of rhOSM in EC cell proliferation, HEC-1B and Ishikawa cells were stimulated with rhOSM (Fig. 3). CCK8 proliferation assays revealed that rhOSM does not have a direct effect on HEC-1B or Ishikawa cell growth.

rhOSM upregulates STAT3 activity in EC cell lines. Although activation of STAT3 by rhOSM occurs in several cell types, it is unclear whether rhOSM can lead to STAT3 activation in EC cells. Thus, EC cells were serum starved and then stimulated with rhOSM (40 ng/ml) for $0 \mathrm{~min}, 5 \mathrm{~min}, 15 \mathrm{~min}, 30 \mathrm{~min}, 1 \mathrm{~h}$, or $2 \mathrm{~h}$ before cells were collected for western blotting (Fig. 4). Basal levels of phosphorylated STAT3 were very low in both cell lines; however, stimulation with rhOSM led to an increase in STAT3 phosphorylation. The peak values appeared after a 15-min (Fig. 4A) and 1-h (Fig. 4B) exposure to rhOSM in HEC-1B and Ishikawa cells, respectively. The total STAT3 protein levels remained fairly stable throughout the time points measured. 

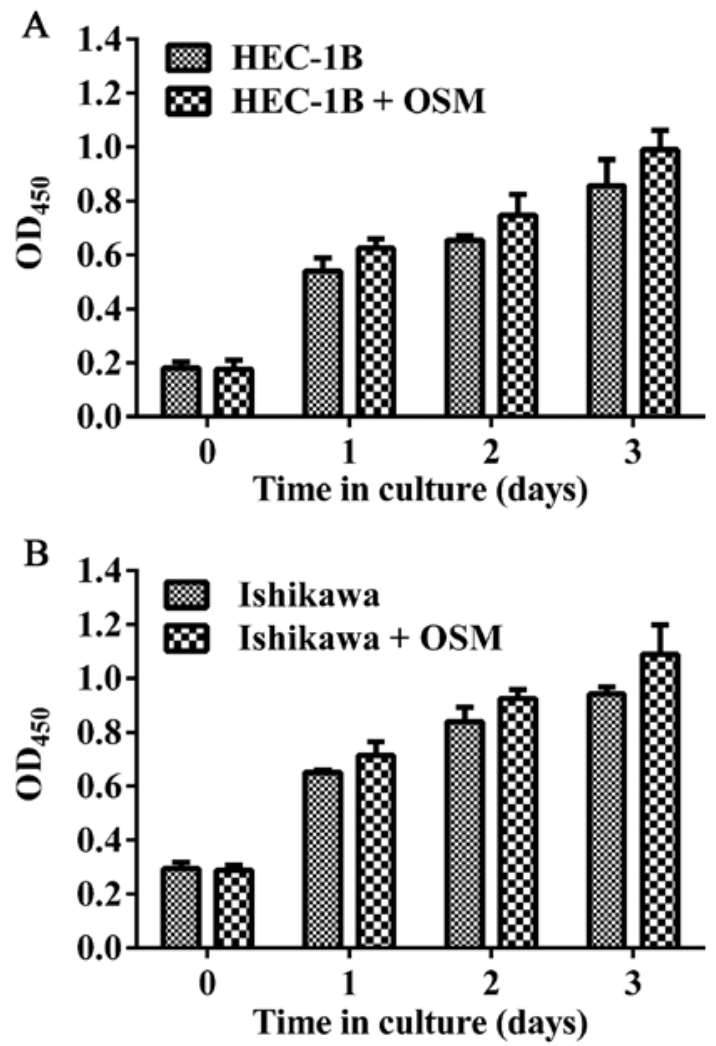

Figure 3. Effect of rhOSM on endometrial cancer (EC) cell proliferation. CCK8 assays were conducted at each time point to examine the proliferation of HEC-1B cells (A) and Ishikawa cells (B) cultured in the absence and presence of rhOSM. Data are shown as the mean $\pm \mathrm{SD}$.

OSM increased VEGF secretion in EC cells. VEGF is the main STAT3-regulated gene product (20). Thus, we assessed the impact of OSM on VEGF expression in HEC-1B cells. Based on qRT-PCR, VEGFA mRNA expression increased in HEC-1B cells after rhOSM stimulation (Fig. 5A). We also detected VEGF secretion in the CM of HEC-1B cells via ELISA. rhOSM stimulation increased VEGF secretion in HEC-1B cells (Fig. 5B). However, VEGF secretion was not increased in cells treated with rhOSM and WP1066.

STAT3 activation mediates OSM-induced angiogenesis. VEGF is a major regulator of tumor angiogenesis (21). To further investigate whether rhOSM affects VEGF-based angiogenesis in ECs, we used three different approaches to investigate whether and how OSM could regulate the behavior of endothelial cells. CM was collected from HEC-1B cells cultured with $\mathrm{C} 0, \mathrm{C} 0 / \mathrm{rhOSM}$, or C0/rhOSM/WP1066 for $24 \mathrm{~h}$. First, to investigate whether rhOSM altered the functional behavior of endothelial cells, we used a tube formation assay. HUVECs were placed on a basement membrane matrix in the presence of CM. Tube formation was quantified by averaging the total length of tubes in three randomly chosen microscope fields. CM from HEC-1B cells stimulated by rhOSM significantly promoted tube formation (Fig. 5D). Second, we tested whether HUVEC migration ability was affected by differing conditions with the use of a transwell chamber assay. The migration ability of HUVECs increased in the C0/rhOSM group, whereas addition of WP1066 partially inhibited these
A HEC-1B

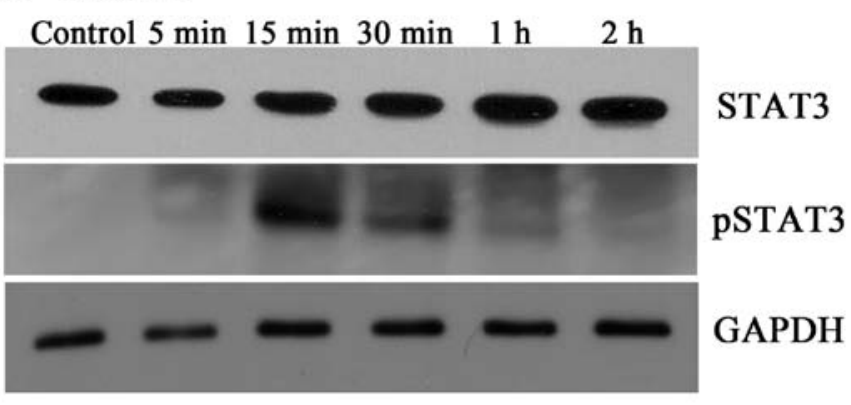

B Ishikawa

Control $5 \mathrm{~min} 15 \mathrm{~min} 30 \mathrm{~min} \quad 1 \mathrm{~h} \quad 2 \mathrm{~h}$

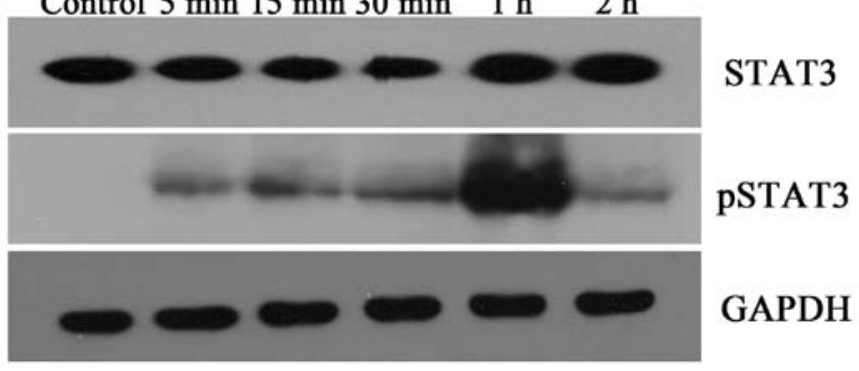

Figure 4. Oncostatin M (OSM) upregulates STAT3 activity in endometrial cancer (EC) cell lines. HEC-1B (A) and Ishikawa (B) cells were treated with $40 \mathrm{ng} / \mathrm{ml} \mathrm{rhOSM}$ for different lengths of time. Cells from the control group were treated with an equal volume DMEM/F12 without FBS. The protein levels of STAT3 and pSTAT3 were examined though western blot analysis. Data are representative of the results from three independent cultures.

effects (Fig. 5C). Thus, OSM may act as a pro-angiogenesis molecule in EC cells by promoting the migration of vascular endothelial cells.

To further confirm this effect in vivo, we performed a mouse angiogenic Matrigel plug assay. We mixed HEC-1B $\mathrm{CM}$ with growth factor-reduced Matrigel and injected the resulting plugs into mouse flanks. The plugs were removed 18 days after injection (Fig. 5E) and were stained with $\mathrm{H} \& \mathrm{E}$ (data not shown) or immunostained for CD34. The inclusion of C0/rhOSM CM led to significantly induced blood vessel formation in Matrigel, whereas the C0/rhOSM/WP1066 CM inhibited these effects. These results suggested that rhOSM stimulation leads to a large increase in angiogenic events and that these events are STAT3 dependent.

Oncogenic role of OSM in an in vivo tumor xenograft model. To further assess the role of OSM in the progression of EC, we performed tumorigenicity assays in nude mice. We constructed HEC-1B cell lines that were stably transfected with plasmid overexpressing either OSM or NC. The transfected cells were then injected into the mice subcutaneously. Five weeks after injection, the sizes and weights of tumors were significantly larger in the OSM-overexpressing group as compared with the NC group (Fig. 6B and C). Tumor tissues were then embedded in paraffin, sectioned, and stained with H\&E and immunolabeled with antibodies against OSM, CD34, Ki67, or PCNA (Fig. 6D). Ki67 and PCNA expression was used to assess proliferation indices. Increased expression of Ki67 and PCNA in the OSM-overexpressing group was consistent with larger tumor volumes in these animals (Fig. 6B-D). Taken 
A

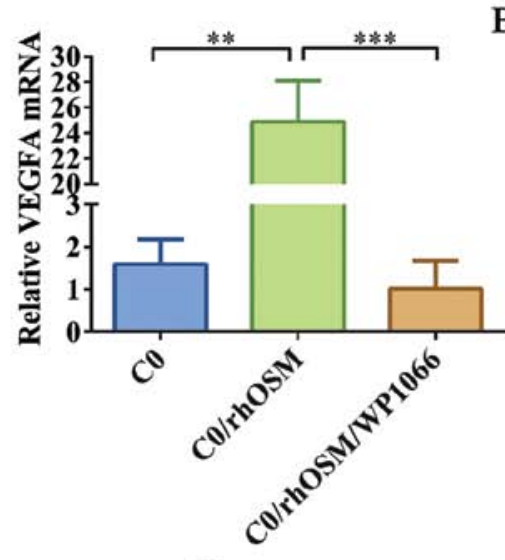

B

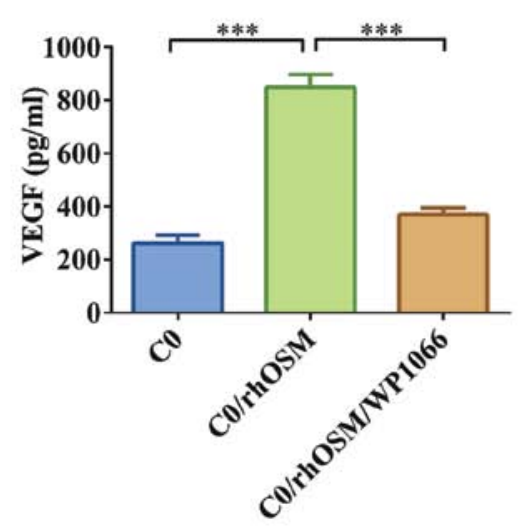

C

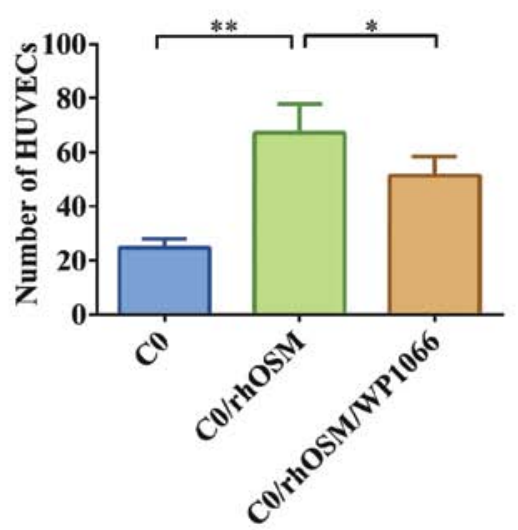

D
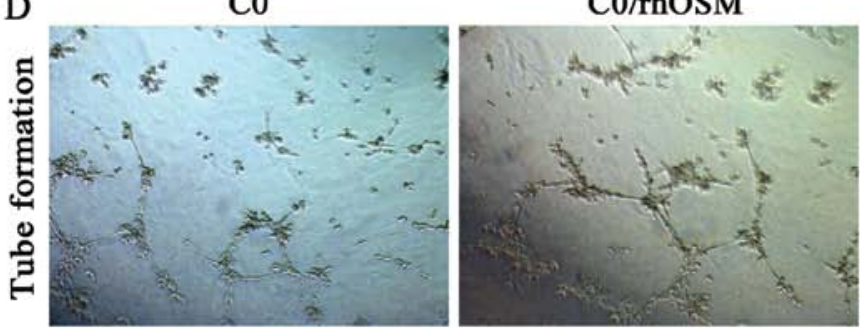

C0/rhOSM/WP1066
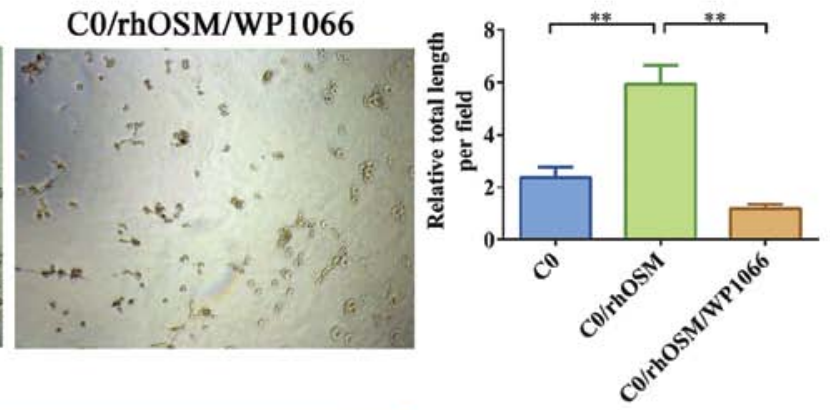

E

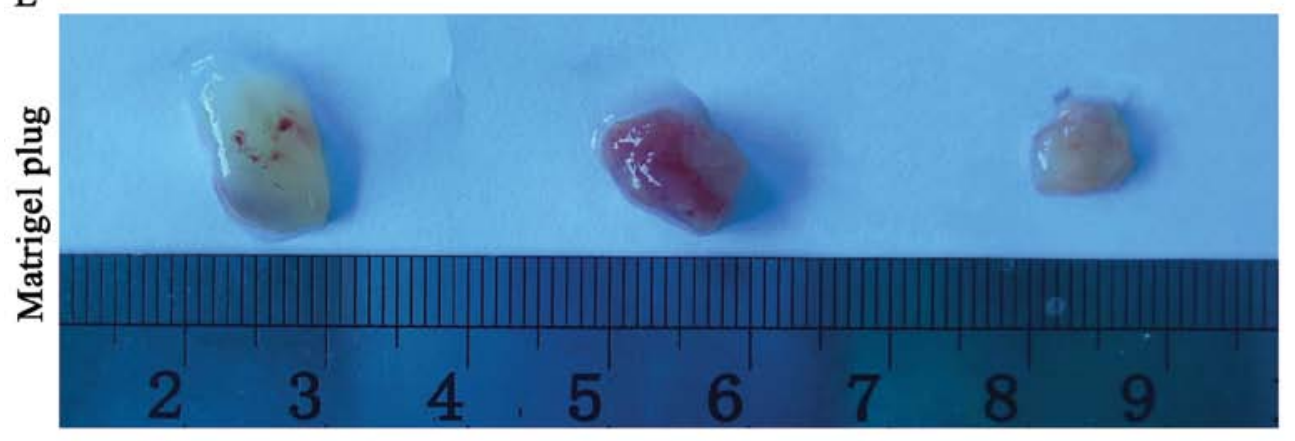

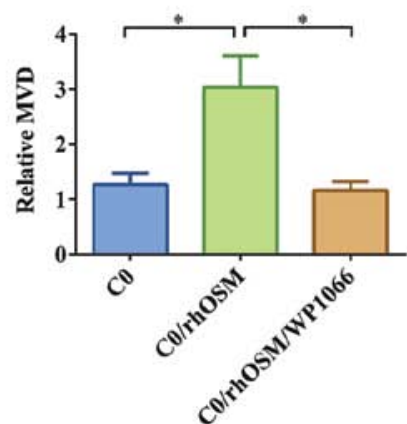

Figure 5. Oncostatin M (OSM) promotes angiogenesis. (A) qPCR analyses of VEGFA in HEC-1B cells treated with rhOSM or rhOSM and WP1066 and incubated for $24 \mathrm{~h}$. (B) The concentration of VEGF in CM collected from HEC-1B cells or from HEC-1B cells treated with rhOSM or rhOSM and WP1066 was determined by ELISA. (C) Transwell migration assays of human umbilical vascular endothelial cells (HUVECs) were performed $24 \mathrm{~h}$ after incubation. (D) HUVEC tube formation assays were performed $16 \mathrm{~h}$ after incubation with HEC-1B CM. Left, representative images are shown at x100 magnification. Right, the relative total tube length formed under the indicated conditions. (E) Matrigel plug assays were performed using HEC-1B CM. Left, representative Matrigel plugs. Right, relative microvessel density (MVD) as determined by immunohistochemical staining for CD34. In each case, three independent experiments were carried out in triplicate; data from one representative experiment are shown as the mean $\pm \mathrm{SD}\left({ }^{*} \mathrm{P}<0.05,{ }^{* * *} \mathrm{P}<0.01,{ }^{* * * *} \mathrm{P}<0.001\right)$.

together, these results suggested an important role for OSM in regulating tumor growth in EC.

\section{Discussion}

The expression of OSM has been studied in several human malignancies and cell types, and the results suggest it has a dual function (22). However, the role of OSM expression or activity in EC remains unclear. Herein, we show that OSM expression was significantly increased in human atypical endometrial hyperplasia and invasive cancers as compared with normal endometrium. Moreover, increased OSM expression levels were positively correlated with the depth of myometrial invasion, disease stage, histological grade and lymph node metastasis of ECs, which are important prognostic factors (23). These data suggest that overexpression of OSM contributes to the progression of human EC.
Solid tumor growth is largely dependent on successful neovascularization, and several factors, the most notable of which are VEGFs, promote tumor angiogenesis. Our findings that VEGF secretion and VEGFA mRNA levels were correlated with different proangiogenic abilities in the $\mathrm{CM}$ from the HEC-1B EC cell line provide further support for the involvement of this mechanism. Increased VEGF expression is found in 56-66\% of EC tumors (24). VEGFA expression is an independent predictor of a poor prognosis in patients with EEC (24-26). Based on the above results, we suggest that OSM may play an important role in angiogenesis regulation in EC.

STAT3 is a $92-\mathrm{kDa}$ transcription factor, whose gene is located on chromosome 17q21 in humans. Activated STAT3 forms homo- and heterodimers that translocate to the nucleus, bind to the promoter region of specific target genes, and regulate gene transcription. Overexpression of STAT3 was found in several cancers, such as lung $(27,28)$, head and neck (29), 
A
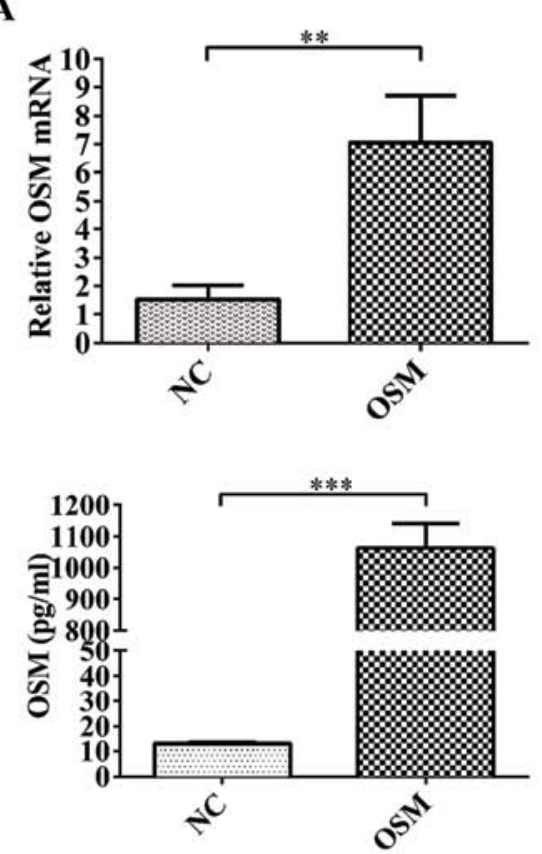

B

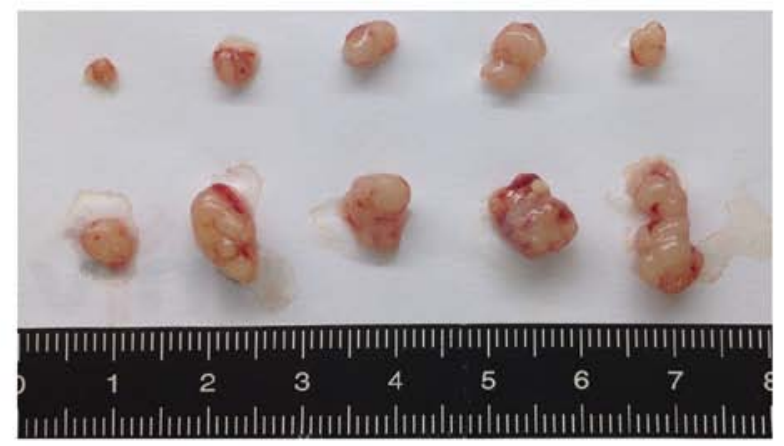

HEC-1B/NC

HEC-1B/OSM
C

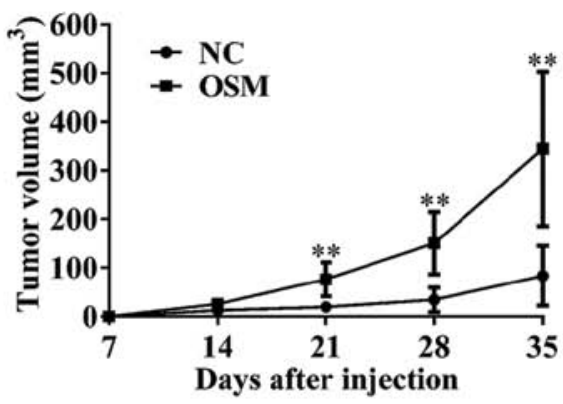

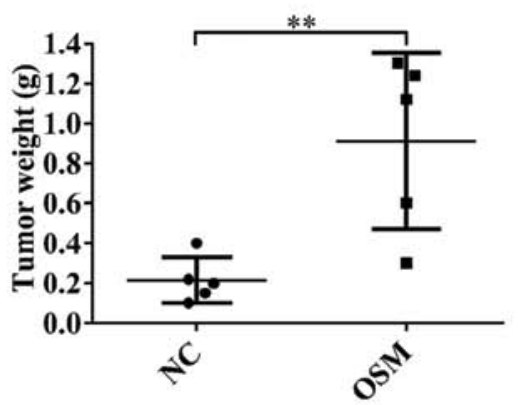

D
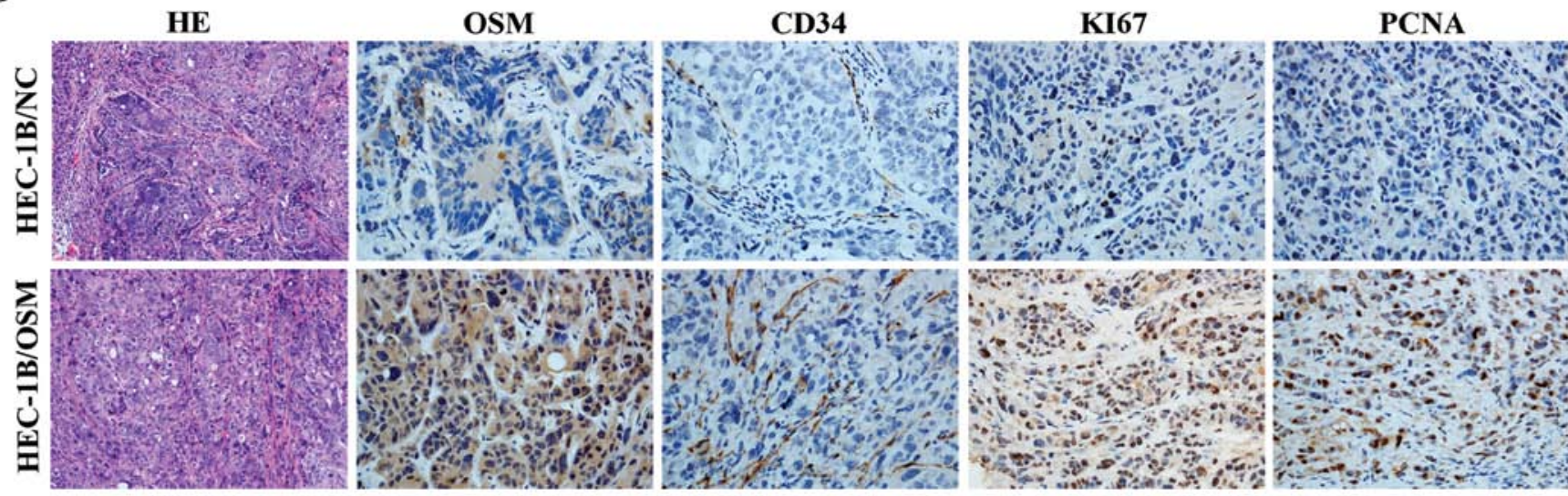

Figure 6. Tumorigenicity assays in nude mice. (A) Stable transfection of HEC-1B cells with oncostatin M (OSM) and negative control (NC) plasmid. The efficiency of transfection was verified by RT-PCR (upper) and ELISA (lower). (B) Tumor formation in the nude mice. (C) Tumor growth curve in nude mice (left) and tumor weight (right) from each nude mouse at the end of 35 days. (A and $C$ ) ${ }^{* *} \mathrm{P}<0.01,{ }^{* * * *} \mathrm{P}<0.001$. (D) Staining with $\mathrm{H} \& \mathrm{E}$ or immunohistochemical staining for OSM, CD34, Ki67 and PCNA in mouse tumor tissues (magnification, x200 for H\&E and x400 for others).

stomach $(30,31)$, and colorectal $(32,33)$ carcinomas. Previous studies have shown that in certain cell lines, OSM induces the activation of STAT3 (34).

In our study, we demonstrated that in HEC-1B and Ishikawa cells, STAT3 was activated after exposure to rhOSM. We further investigated the effects of rhOSM on the migration and invasion of EC cells and found that rhOSM markedly promoted cell migration and invasion in HEC-1B and Ishikawa cells. These findings are consistent with our immunohistochemical analysis, which showed that higher expression of OSM is found in tumors that displayed a greater depth of myometrial invasion. However, the effect was reversed when WP1066 was added. This suggests that OSM-induced migration and invasion are both regulated by the signaling of OSM-induced STAT3 activation. We also showed that rhOSM promoted VEGF secretion in HEC-1B cells and that the CM taken from these treated cells led to an increase in tube length in HUVECs in the tube formation assay and increased MVD in plugs in the mouse Matrigel plug assay. This phenomenon was reversed when the cells were exposed to WP1066. Since activated STAT3 binds to the VEGF promoter (15), rhOSM may activate STAT3, which thereby induces VEGF expression. However, our data do not completely rule out the possibility that other signaling pathways, in addition to STAT3, are involved. The identification of additional rhOSM-induced pathways and the determination of the specific molecular mechanism responsible for the OSM-STAT3 interaction are aspects that warrant further study.

Whereas some studies have confirmed that OSM inhibits proliferation in melanoma, osteosarcoma, and neuroblastoma cancer cells $(35,36)$, other studies have shown a direct proproliferative effect on Kaposi's sarcoma and Ewing sarcoma cells $(37,38)$. In our study, OSM did not directly stimulate proliferation of either HEC-1B or Ishikawa cells in vitro; however, in the mouse xenograft model, it was able to promote proliferation and resulted in larger tumor volumes. Recent 
research shows that overexpression of OSM promotes tumor growth, and does so through alteration of the tumor environment with the accumulation of M2 macrophages (39). Whether this kind of mechanism exists in ECs is still unclear and requires further investigation.

In summary, our study demonstrates that OSM plays important roles during EC progression, especially in the regulation of angiogenesis. These findings suggest that OSM may be a valuable prognostic biomarker for EC progression and that it could offer a novel potential therapeutic strategy for ECs. Although our results are promising, additional investigations are required to further define the long-term consequences of anti-OSM treatment.

\section{Acknowledgements}

We thank Yue-qin Tang and Yan Hong (Center Laboratory of Shanghai First People's Hospital Affiliated to Shanghai Jiao Tong University, Shanghai, China) and Xiao-ying $\mathrm{He}$ (Department of Obstetrics and Gynecology, International Peace Maternity and Child Health Hospital Affiliated to Shanghai Jiao Tong University, Shanghai, China) for excellent technical assistance. This study was supported by the National Natural Science Foundation of China (no. 81472427, no. 81272885, no. 81172476), Doctorial Innovation Fund of Shanghai Jiao Tong University School of Medicine (no. BXJ201338).

\section{References}

1. Siegel R, Naishadham D and Jemal A: Cancer statistics, 2013. CA Cancer J Clin 63: 11-30, 2013.

2. Kandoth C, Schultz N, Cherniack AD, Akbani R, Liu Y, Shen H, Robertson AG, Pashtan I, Shen R, Benz CC, et al; Cancer Genome Atlas Research Network: Integrated genomic characterization of endometrial carcinoma. Nature 497: 67-73, 2013.

3. Gadducci A, Cosio S and Genazzani AR: Old and new perspectives in the pharmacological treatment of advanced or recurrent endometrial cancer: Hormonal therapy, chemotherapy and molecularly targeted therapies. Crit Rev Oncol Hematol 58: 242-256, 2006

4. Lahiri T, Laporte JD, Moore PE, Panettieri RA Jr and Shore SA: Interleukin-6 family cytokines: Signaling and effects in human airway smooth muscle cells. Am J Physiol Lung Cell Mol Physiol 280: L1225-L1232, 2001.

5. Grenier A, Dehoux M, Boutten A, Arce-Vicioso M, Durand G, Gougerot-Pocidalo MA and Chollet-Martin S: Oncostatin M production and regulation by human polymorphonuclear neutrophils. Blood 93: 1413-1421, 1999.

6. Horn D, Fitzpatrick WC, Gompper PT, Ochs V, BoltonHansen M, Zarling J, Malik N, Todaro GJ and Linsley PS: Regulation of cell growth by recombinant oncostatin M. Growth Factors 2: 157-165, 1990.

7. Douglas AM, Goss GA, Sutherland RL, Hilton DJ, Berndt MC, Nicola NA and Begley CG: Expression and function of members of the cytokine receptor superfamily on breast cancer cells. Oncogene14: 661-669, 1997.

8. Brounais B, Chipoy C, Mori K, Charrier C, Battaglia S, Pilet P, Richards CD, Heymann D, Rédini F and Blanchard F: Oncostatin $\mathrm{M}$ induces bone loss and sensitizes rat osteosarcoma to the antitumor effect of Midostaurin in vivo. Clin Cancer Res 14: $5400-5409,2008$.

9. Godoy-Tundidor S, Cavarretta IT, Fuchs D, Fiechtl M, Steiner H, Friedbichler K, Bartsch G, Hobisch A and Culig Z: Interleukin-6 and oncostatin $\mathrm{M}$ stimulation of proliferation of prostate cancer $22 \mathrm{Rv} 1$ cells through the signaling pathways of p38 mitogenactivated protein kinase and phosphatidylinositol 3-kinase. Prostate 64: 209-216, 2005.

10. Li Q, Zhu J, Sun F, Liu L, Liu X and Yue Y: Oncostatin M promotes proliferation of ovarian cancer cells through signal transducer and activator of transcription 3. Int J Mol Med 28: 101-108, 2011.
11. Mori S, Murakami-Mori K and Bonavida B: Oncostatin M (OM) promotes the growth of DU 145 human prostate cancer cells, but not PC-3 or LNCaP, through the signaling of the OM specific receptor. Anticancer Res 19: 1011-1015, 1999.

12. Gearing DP and Bruce AG: Oncostatin M binds the high-affinity leukemia inhibitory factor receptor. New Biol 4: 61-65, 1992.

13. Gearing DP, Comeau MR, Friend DJ, Gimpel SD, Thut CJ, McGourty J, Brasher KK, King JA, Gillis S, Mosley B, et al: The IL-6 signal transducer, gp130: An oncostatin M receptor and affinity converter for the LIF receptor. Science 255: 1434-1437, 1992.

14. Mosley B, De Imus C, Friend D, Boiani N, Thoma B, Park LS and Cosman D: Dual oncostatin M (OSM) receptors. Cloning and characterization of an alternative signaling subunit conferring OSM-specific receptor activation. J Biol Chem 271: 32635-32643, 1996.

15. Niu G, Wright KL, Huang M, Song L, Haura E, Turkson J, Zhang S, Wang T, Sinibaldi D, Coppola D, et al: Constitutive Stat3 activity up-regulates VEGF expression and tumor angiogenesis. Oncogene 21: 2000-2008, 2002.

16. Folkman J: Angiogenesis in cancer, vascular, rheumatoid and other disease. Nat Med 1: 27-31, 1995.

17. Risau W: Mechanisms of angiogenesis. Nature 386: 671-674, 1997.

18. Creasman W: Revised FIGO staging for carcinoma of the endometrium. Int J Gynaecol Obstet 105: 109, 2009.

19. Liao Y, Lu W, Che Q, Yang T, Qiu H, Zhang H, He X, Wang J, Qiu M, Zou Y, et al: SHARP1 suppresses angiogenesis of endometrial cancer by decreasing hypoxia-inducible factor- $1 \alpha$ level. PLoS One 9: e99907, 2014.

20. Calò V, Migliavacca M, Bazan V, Macaluso M, Buscemi M, Gebbia N and Russo A: STAT proteins: From normal control of cellular events to tumorigenesis. J Cell Physiol 197: 157-168, 2003.

21. Kim KJ, Li B, Winer J, Armanini M, Gillett N, Phillips HS and Ferrara N: Inhibition of vascular endothelial growth factorinduced angiogenesis suppresses tumour growth in vivo. Nature 362: 841-844, 1993.

22. Tanaka $\mathbf{M}$ and Miyajima A: Oncostatin M, a multifunctional cytokine. Rev Physiol Biochem Pharmacol 149: 39-52, 2003.

23. Uharcek P: Prognostic factors in endometrial carcinoma. J Obstet Gynaecol Res 34: 776-783, 2008.

24. Hirai M, Nakagawara A, Oosaki T, Hayashi Y, Hirono M and Yoshihara T: Expression of vascular endothelial growth factors (VEGF-A/VEGF-1 and VEGF-C/VEGF-2) in postmenopausal uterine endometrial carcinoma. Gynecol Oncol 80: 181-188, 2001.

25. Kamat AA, Merritt WM, Coffey D, Lin YG, Patel PR, Broaddus R, Nugent E, Han LY, Landen CN Jr, Spannuth WA, et al: Clinical and biological significance of vascular endothelial growth factor in endometrial cancer. Clin Cancer Res 13: 7487-7495, 2007.

26. Yokoyama Y, Sato S, Futagami M, Fukushi Y, Sakamoto T, Umemoto $M$ and Saito Y: Prognostic significance of vascular endothelial growth factor and its receptors in endometrial carcinoma. Gynecol Oncol 77: 413-418, 2000.

27. Haura EB, Zheng Z, Song L, Cantor A and Bepler G: Activated epidermal growth factor receptor-Stat-3 signaling promotes tumor survival in vivo in non-small cell lung cancer. Clin Cancer Res 11: 8288-8294, 2005.

28. Jiang R, Jin Z, Liu Z, Sun L, Wang L and Li K: Correlation of activated STAT3 expression with clinicopathologic features in lung adenocarcinoma and squamous cell carcinoma. Mol Diagn Ther 15: 347-352, 2011.

29. Seethala RR, Gooding WE, Handler PN, Collins B, Zhang Q, Siegfried JM and Grandis JR: Immunohistochemical analysis of phosphotyrosine signal transducer and activator of transcription 3 and epidermal growth factor receptor autocrine signaling pathways in head and neck cancers and metastatic lymph nodes. Clin Cancer Res 14: 1303-1309, 2008.

30. Gong W, Wang L, Yao JC, Ajani JA, Wei D, Aldape KD, Xie K, Sawaya R and Huang S: Expression of activated signal transducer and activator of transcription 3 predicts expression of vascular endothelial growth factor in and angiogenic phenotype of human gastric cancer. Clin Cancer Res 11: 1386-1393, 2005.

31. Lee J, Kang WK, Park JO, Park SH, Park YS, Lim HY, Kim J, Kong J, Choi MG, Sohn TS, et al: Expression of activated signal transducer and activator of transcription 3 predicts poor clinical outcome in gastric adenocarcinoma. APMIS 117: 598-606, 2009. 
32. Lassmann S, Schuster I, Walch A, Göbel H, Jütting U, Makowiec F, Hopt U and Werner M: STAT3 mRNA and protein expression in colorectal cancer: Effects on STAT3-inducible targets linked to cell survival and proliferation. J Clin Pathol 60: 173-179, 2007.

33. Morikawa T, Baba Y, Yamauchi M, Kuchiba A, Nosho K, Shima K, Tanaka N, Huttenhower C, Frank DA, Fuchs CS, et al: STAT3 expression, molecular features, inflammation patterns, and prognosis in a database of 724 colorectal cancers. Clin Cancer Res 17: 1452-1462, 2011.

34. Fossey SL, Bear MD, Kisseberth WC, Pennell M and London CA: Oncostatin M promotes STAT3 activation, VEGF production, and invasion in osteosarcoma cell lines. BMC Cancer 11: 125, 2011.

35. Chipoy C, Berreur M, Couillaud S, Pradal G, Vallette F, Colombeix C, Rédini F, Heymann D and Blanchard F: Downregulation of osteoblast markers and induction of the glial fibrillary acidic protein by oncostatin $\mathrm{M}$ in osteosarcoma cells require PKCdelta and STAT3. J Bone Miner Res 19: 1850-1861, 2004
36. Chipoy C, Brounais B, Trichet V, Battaglia S, Berreur M, Oliver L, Juin P, Rédini F, Heymann D and Blanchard F: Sensitization of osteosarcoma cells to apoptosis by oncostatin $\mathrm{M}$ depends on STAT5 and p53. Oncogene 26: 6653-6664, 2007.

37. David E, Tirode F, Baud'huin M, Guihard P, Laud K, Delattre O, Heymann MF, Heymann D, Redini F and Blanchard F: Oncostatin $\mathrm{M}$ is a growth factor for Ewing sarcoma. Am J Pathol 181: 1782-1795, 2012.

38. Amaral MC, Miles S, Kumar G and Nel AE: Oncostatin-M stimulates tyrosine protein phosphorylation in parallel with the activation of p42MAPK/ERK-2 in Kaposi's cells. Evidence that this pathway is important in Kaposi cell growth. J Clin Invest 92: 848-857, 1993.

39. Lauber S1, Wong S, Cutz JC, Tanaka M, Barra N, Lhoták S, Ashkar A and Richards CD: Novel function of Oncostatin M as a potent tumour-promoting agent in lung. Int J Cancer 136: 831-843 2015. 